\title{
Solar Light Guide and Window Design Based on Energy Conservation and Renovation of Old Office Buildings
}

\author{
Qiuling Chen ${ }^{1}, \quad$ Zerui Pan ${ }^{2}, \quad$ Junyu Li $* 2$, Nianzhong Gan ${ }^{2}$ \\ ${ }^{1}$ Wuhan University of Technology, School of civil engineering and architecture \\ ${ }^{2}$ Wuhan University of Technology, School of energy and power engineering
}

\begin{abstract}
A multiple of researches have been conducted at home and abroad on indoor natural lighting. However, the current lighting methods suffer from different degrees of defects, with high operation and maintenance costs. Therefore, this paper proposes a new type of multifunctional lighting window, integrating the lens fiber optic light guide device and the photovoltaic film, forming a new type of light window integrating optical lens and photovoltaic film, which can effectively meet the needs of energy conservation and environmental protection.
\end{abstract}

\section{Introduction}

With the development of China's economy and the acceleration of urbanization, the proportion of energy consumption of building in China's total energy consumption has also increased year on year. Since the beginning of this century, the proportion of energy consumption of buildings in China's total energy consumption has exceeded 27\%. Public buildings are the main part of the city, and also the major consumers of energy and resources, which enjoys greater potential for energy conservation than residential buildings.

In large office buildings(as shown in Figure 1), lighting energy consumption can account for $25 \%$ to $30 \%$ of its total energy consumption due to its large and deep structural features and the use of constant light sources. The energy consumption ratio of old office buildings is higher as they have poor lighting as well as outdated equipment. If daytime illumination can be achieved with natural light instead of lamps, building energy consumption will be effectively reduced. Therefore, exploring a lighting method that can be applied to the renovation of existing buildings, and reducing the lighting energy consumption of existing buildings are of great significance to realizing energy-saving renovation of buildings and improving the green development level of the construction field.

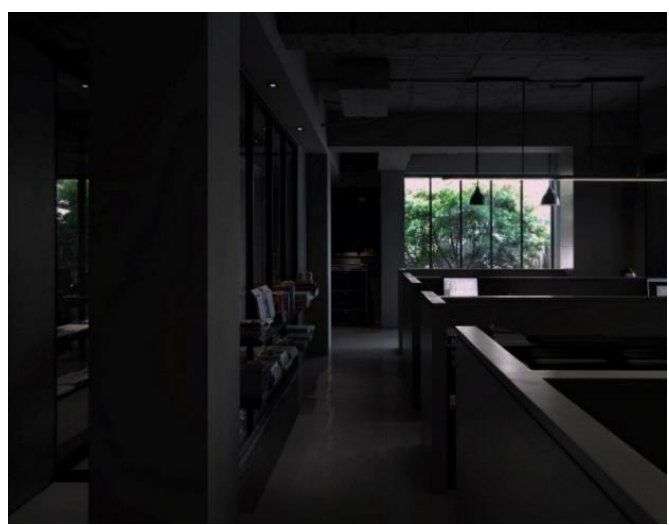

Fig.1 Indoor lighting rendering of existing buildings

\section{An overall design scheme for a new type of lighting window integrating optical lens and photovoltaic film}

\subsection{Structural design concept}

This paper proposes a new type of multifunctional lighting window, integrating lens fiber lighting device ${ }^{[1,2]}$ and photovoltaic film to form a new type of lighting window that integrates optical lens and photovoltaic film. The basic design thought is shown in Figure 2. Target at the defect of traditional light guide methods' difficulty in achieving high efficiency light guide and in existing applications in existing buildings, optical fiber is applied as a light guide medium to achieve long-distance light guide; for the defects of the attenuation of the illumination in the deep direction of existing natural light in big and deep rooms, the combination of lighting equipment and windows is applied to reduce the changes to the existing building structure; for the problem that natural light 
intensity is difficult to maintain constant and affected by the climate, LED, as the compensation light source, is applied to achieve constant indoor light intensity; as the compensation light source, the solar tracking device, and the corresponding control equipment of the system itself require power supply, photovoltaic thin film batteries are installed on both sides of the condenser to power the system, achieving the goal of no energy consumption for the system per se.

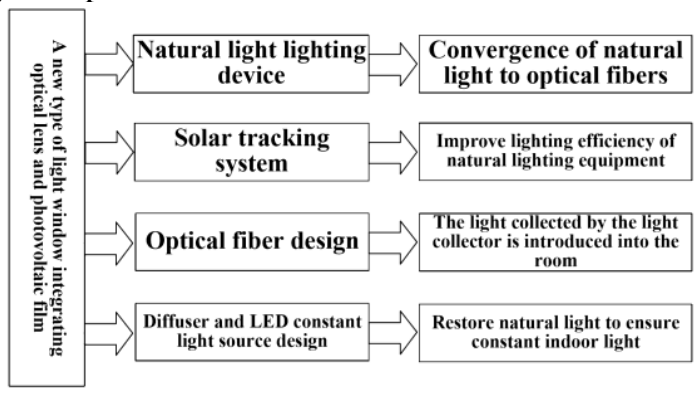

Fig. 2 The diagram of a new type of lighting window system integrating optical lens and photovoltaic film

\subsection{Overall Design}

Lens fiber optic light guide structure-glass window integrated design scheme is adopted. The upper part of the glass window is an optical fiber condenser device, and the protruding structure has the effect of sun shading, and collects sunlight to guide the natural light into the room through the optical fiber; Photovoltaic film is attached to the lower side of the side face and the front face of the optical fiber condenser device to convert solar energy into electricity for the normal operation of the solar tracking device, so that the angle of the lens group is changed, and excess electric energy is stored in the battery. When the weather is unfavorable, the battery powers the LED constant light compensation system to ensure indoor light intensity. The preliminary design of the program is shown in Figure 3:

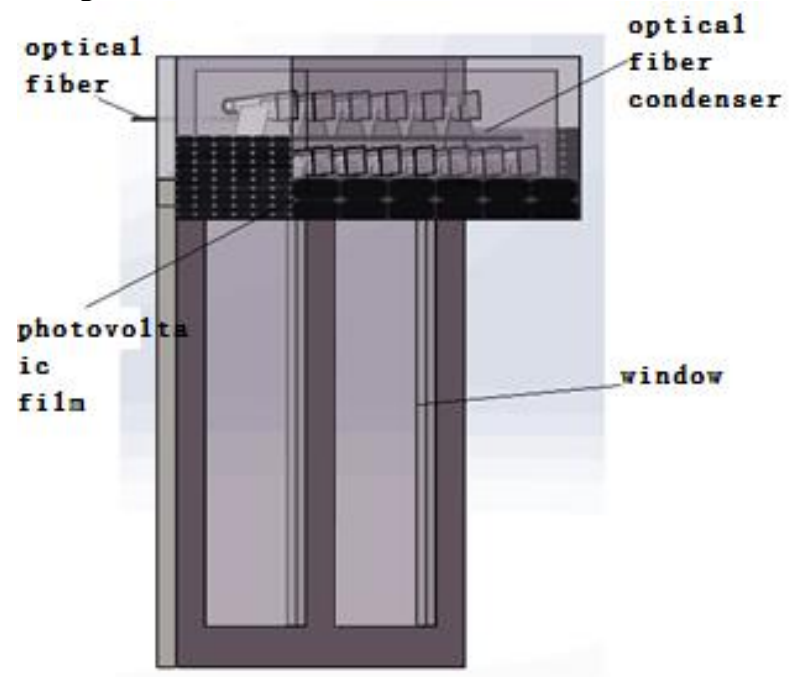

Fig. 3 A new type of lighting window integrating optical lens and photovoltaic film

\subsection{Optical fiber condenser design}

The overall design of the condenser and light guide system was completed ${ }^{[3]}$. By comparing various lenses and referring to the structure of the concentrating system at home and abroad, the Fresnel lens-collimating lens was defined as a unit structure. After the three-dimensional model was established, the concentrating efficiency of the model was analyzed with ANSYS and matlab software, and the structure was optimized. The structure is shown in Figure 4:

A, lighting unit design: Lens 1 is Fresnel lens. This article applies $20 \mathrm{~cm} * 20 \mathrm{~cm}$ Fresnel lens as a condenser, with a focal length of $300 \mathrm{~mm}$, the main focal plane diameter of $4 \mathrm{~cm}$, of PMMA material, and refractive index of 1.49. Lens 2 is a collimating lens with a bore diameter of $4 \mathrm{~cm}$. The lens 2 is directly coupled with a plastic illumination optical fiber. The fiber cladding has a diameter of $20 \mathrm{~mm}$ and a numerical aperture of 0.5 . Each Fresnel lens is combined with an ordinary convex lens and 8 plastic optical fibers to form a lighting modular structure. In addition, each of the lighting units filters the sunlight to effectively reduce the heat carried by the normal sunlight, thereby reducing the indoor lighting temperature.

B. Application of the solar tracker: Place the designed lighting unit on the solar tracker so that it changes as the time of day changes and the angle of the sun changes, in order to better receive the irradiation of sunlight to ensure the lighting efficiency and actual effect of the fiber condenser device. 


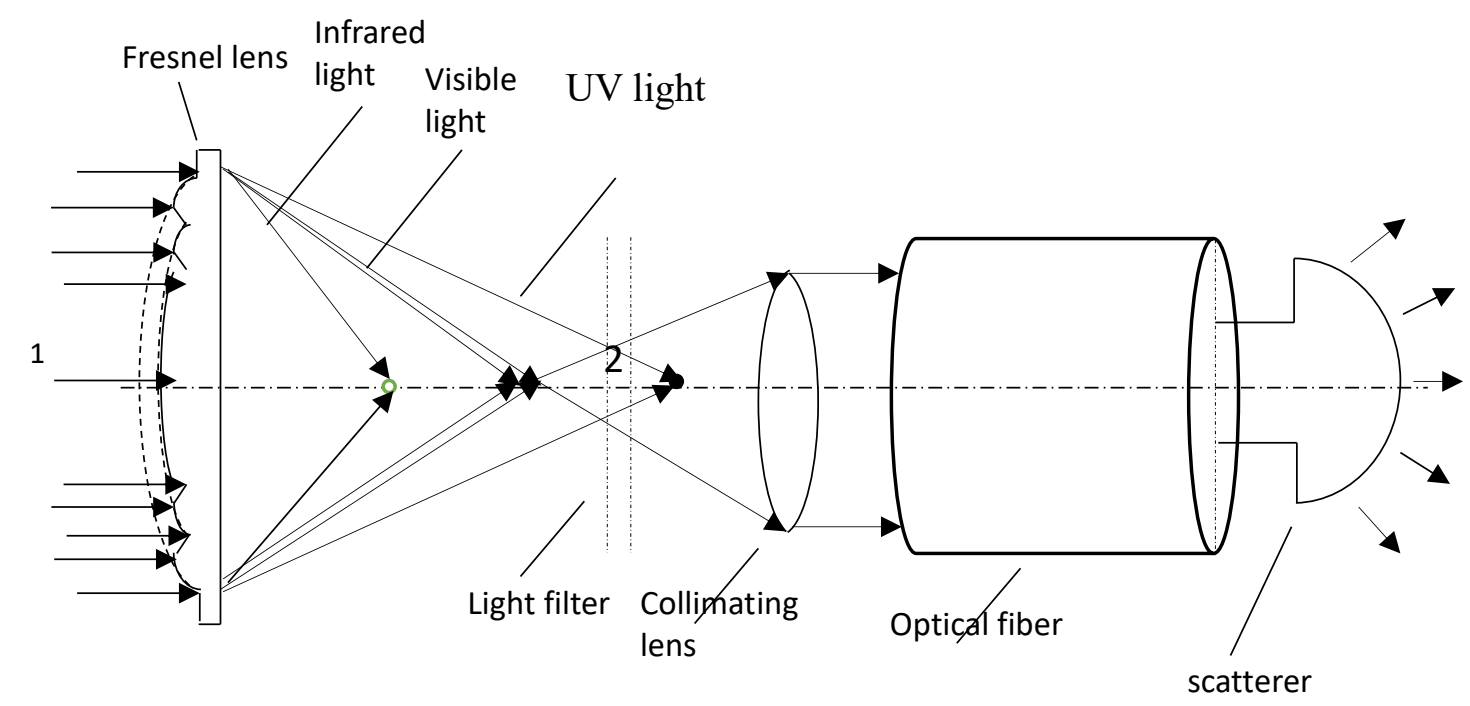

Fig. 4 Schematic design of the condenser and light guide system

\subsection{Technical design of power distribution system}

Light energy is converted into electrical energy via a photovoltaic film, stabilized by a voltage regulator and sent to a solar tracker and a battery via a power distributor, respectively, for the normal operation of the solar tracker and storage for the battery; when the LED constant light compensation system is triggered, the battery will provide power for the LED to compensate for indoor lighting ${ }^{[4]}$. The workflow is shown in Figure 5:

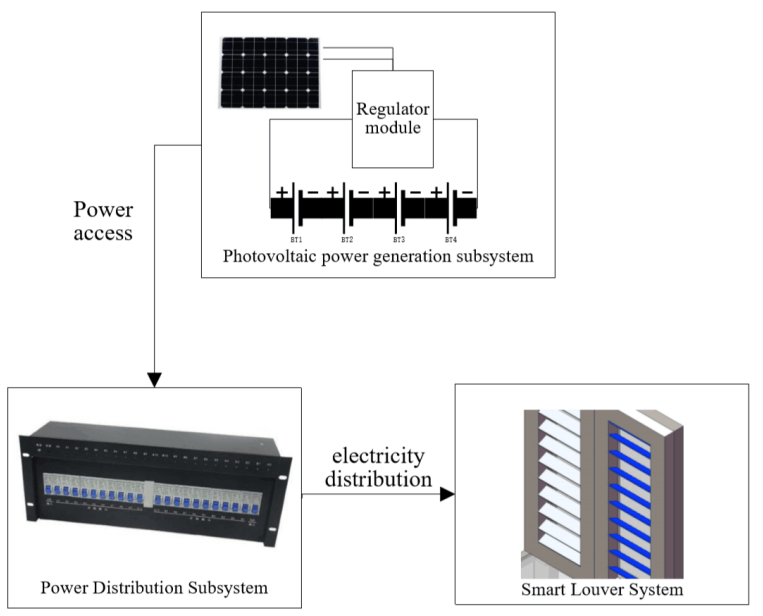

Fig. 5 Schematic diagram of power distribution system

\subsection{LED constant light compensation technology design}

As it is difficult to keep the natural light intensity constant, which is influenced by the weather, LED is applied as a compensation light source to achieve constant indoor light intensity.
The LED compensation light source is integrated with the natural light diffuser (as shown in FIG. 6), and the LED light source is arranged around the natural light diffuser. In the meantime, the illumination monitoring sensor is arranged at the end of the lamp shade to monitor the brightness of the lighting equipment; when the illumination cannot meet the indoor lighting demand, the LED compensation light source performs the supplement of light according to the set illumination value to ensure the constant indoor illumination. According to the relevant regulations of architectural lighting design standard in the GB 50034-2013, the office building's standard value of illumination varies between 200-750 lx, depending on the specific location. Therefore, the adjustment range of illumination is preferably between 200-750 1x.

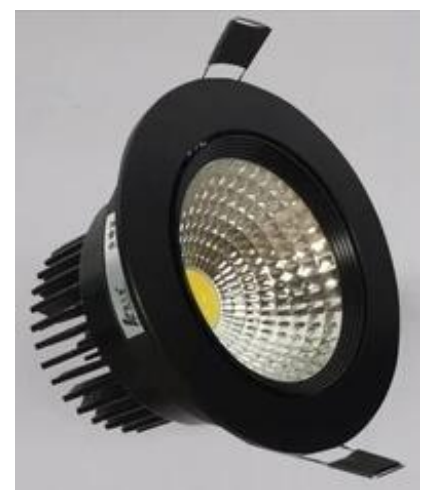

Fig. 6 Natural light diffuser shade

Dimming lighting control system takes illumination as a control parameter, the light source as the control object, in the dawn or evening when the sun gradually enhances or gradually weakens, the light intensity of the illumination source is adjusted dynamically, so that the indoor illumination remains stable. The system can be divided into the control part with the single-chip microcomputer as the core, the signal input part of the light intensity sensor, the control quantity output part of 
the LED light source, and the input-output part for interaction. The illumination information is input to the SCM after sampling by the optical sensor, and the actual illumination value is compared with the set illumination value within the SCM to calculate a digital control quantity for compensating the illumination. The digital control adjusts the PWM duty cycle to control the effective value of the output voltage, and then drives the LED light source through the execution circuit.

\section{Analysis of performance and efficiency of multi-function lighting window}

\subsection{Environmental suitability analysis}

This paper targets at high consumption during daytime and features such as large depth, large area, poor lighting, etc ${ }^{[5]}$. Therefore, in order to ensure the light intensity of the room and the balanced illumination, the building often requires long-term use of electric lights during the daytime, representing one of the factors that the power consumption index of illumination is 2 to 3 times that of ordinary houses. In view of this, this project is designed to effectively solve the problem of high indoor lighting consumption during the daytime of the existing office building, and it also ensures the stability of the indoor illumination intensity and the average illumination intensity, with sound energy-conserving effect and application prospects.

\subsection{Analytical calculation of energy conservation and emission reduction benefits}

Compared with traditional windows, the new sunlight window with solar tracking and fiber transmission enjoys many advantages and economic benefits in indoor lighting, heat insulation, etc. It has high promotion value in office buildings, and is summarized as follows:

Taking a comprehensive building as a research object, the building has a total of 29 floors, including 27 floors on the ground and 2 floors under the ground. The building height is $104 \mathrm{~m}$. The total construction area is $46,000 \mathrm{~m}^{2}$. Among them, the 1 st to 14 th floors are office areas with a building area of 20,000 $\mathrm{m}^{2}$, and the working hours are from 8:00 to 19:00 on working days. This design can reduce the lighting energy consumption of the building and the energy consumption of the air conditioner respectively. If this building is taken as an example, the energy saving and emission reduction effects of this design in terms of lighting and air conditioning can be obtained separately:

Lighting energy consumption: Assume that 3 products are installed in the office, and the average annual conserved energy is $4811.25 \mathrm{kWh}$. For an office area with a floor area of about $20,000 \mathrm{~m}^{2}$ in the middle and lower floors of 1 to 14 floors in a 29-storey complex, the annual average conserved power can reach $962,250 \mathrm{kWh}$. From this we can see that this product enjoys a high energy efficiency.

Air-conditioning energy consumption: The power consumption per unit area of the office building is 48.6 $\mathrm{kWh} /\left(\mathrm{m}^{2} \cdot \mathrm{a}\right)$, and the total energy consumption of the office area with a total area of $20,000 \mathrm{~m}^{2}$ is $48.6 \mathrm{kWh} /$ $\mathrm{m}^{2} \times 20000 \mathrm{~m}^{2}=972,000 \mathrm{kWh}$. The annual air-conditioning energy consumption can be calculate taking $41.1 \%$ of the total energy consumption of the building as airconditioning power consumption, that is $972000 \mathrm{kWh} \times$ $41.1 \%=402408 \mathrm{kWh}$. The shielding of the sunlight by the optical elements on each window can effectively reduce the indoor air conditioning energy consumption in the summer, with high application value and energy conserving benefit.

\section{Conclusion}

The multifunction lighting window designed in this paper is based on the "Thirteenth Five-Year Plan". Currently, about 100 million square meters of old buildings in China are in urgent need of renovation, and it insists on innovative, coordinated, green, open, and shared development concepts, based on the requirements of application, economy, safety, green and beautiful development, aiming at energy conservation, emission reduction and environmental protection, supported by advanced technology, with market-oriented operation as the main method, and the energy consumption reduction of old residential buildings as focus, to encourage and guide the reform of the heat supply system as the driving force, providing a direction for establishing and improving energy-conserving renovation of old residential buildings and accelerating energy-conserving renovation of old residential buildings.

\section{References}

1. Meng Qiang. Optical Fiber Indoor Illumination System Based on Solar Tracking [D]. Shandong University, 2012.

2. Chen Yanjun. Research on Natural Lighting of Common Classrooms in Colleges and Universities in Chongqing Based on Side Windows [D]. Chongqing University, 2014.

3. Li Peng, Wu Heli, Yang Peihuan, et al. General Design Method and Efficiency Analysis of Fresnel Condenser Lenses [J]. Journal of Wuhan University of Technology, 2010(6):62-66.

4. Zhang Kaili, Deng Yanmei, Gao Ce. Intelligent Window Shades System Based on Photovoltaic Power Generation $[\mathrm{J}]$. Science \& Technology Information, 2014, 12(21):4-5.

5. Ma Ye. Research on Lighting and Energy Consumption of Unilateral Windows in Public Buildings [D]. Tianjin University, 2007. 